\title{
STATISTICAL LITERACY IN PUBLIC DEBATE - EXAMPLES FROM THE UK 2015 GENERAL ELECTION
}

\author{
PHOEBE ARNOLD \\ Full Fact \\ phoebe@fullfact.org
}

\begin{abstract}
Full Fact is an independent, non-partisan fact-checking charity. A particular focus is the analysis of factual claims in political debate in the UK; for example, factchecking claims and counterclaims made during Prime Minister's questions. Facts do not appear in a vacuum as they are often used as key elements in an effort to make a coherent argument. This paper describes a number of case histories where facts are disputed, drawn from our election work, to give an overview of the contemporary state of statistical literacy among politicians and the media. Common pitfalls in politicians' claims are set out, along with descriptions of our attempts to close the communication gap between different communities.
\end{abstract}

Keywords: Statistics education research; UK general election 2015; Public debate; Media statistical literacy

\section{FULL FACT AND THE UK 2015 GENERAL ELECTION}

In the late 1990s and early 2000s, Statistics Norway ran an experiment spanning three elections. In the weeks running up to polling day, they published 20 presentations on statistics they thought were relevant to the election campaign, from educational attainment and population structure to regional economic data and health and social care. Statistics Norway's head, Svein Longva announced that, "The response has been overwhelmingly positive and there have been no complaints that Statistics Norway interferes in the political debate or presents biased information" (Longva, 2014).

Full Fact sought funding to run a two-election experiment - inspired by Statistics Norway and other international efforts - to bring the public reliable information without any spin. Partnerships with academic research organisations were developed from 2012, including with the National Foundation for Educational Research, the University of Oxford's Migration Observatory, the Institute for Criminal Policy Research, and the Health Foundation. The question collaborators were trying to answer was: "Can we work together, simply to inform voters, with the same concerted effort as the political parties put into winning people's votes?" The 2015 election was intended to be the testing ground, with lessons learnt to be applied at scale in 2020.

The project had two main stages. From January to March, Full Fact published briefings, either written by or reviewed by their expert partners, on a variety of topics including the effect of migrants on the job market, the national debt and the national deficit, the NHS funding gap, and performance of academies versus maintained schools. From the end of March until the election on 7 May, Full Fact ran a rapid-response factchecking centre from 6 a.m. to midnight, seven days per week, fact-checking claims in

Statistics Education Research Journal, 16(1), 217-227, http://iase-web.org/Publications.php? $p=$ SERJ

(C) International Association for Statistical Education (IASE/ISI), May, 2017 
press releases, politicians' speeches, and social media output; and responding to queries from the media and public.

Full Fact focused its publicity efforts on broadcast media: according to Ofcom (2014), 75\% people say they get their news from television. However, its reach was not limited to these channels: newspapers across the political spectrum cited Full Fact research and its social media following increased from 26,200 to 29,800 on Twitter and from 7,600 to 8,900 on Facebook. Full Fact's election work forms a rich basis on which to assess the contemporary state of statistical literacy among politicians and the media, drawing on both fact checks and coverage by and engagement with media outlets. The Election Centre was supported through funding from the Nuffield Foundation, a crowdfunding campaign, and over 100 volunteers including statisticians from the Office for National Statistics (ONS) and the market research company Ipsos MORI. Staff and volunteers were split into three teams:

1. The monitoring team extracted factual claims from the press and broadcast programmes, party press releases and social media, and politicians' speeches, and put these claims into a database.

2. The analysis team selected claims to fact-check, often in line with the big political claim of the day but also important claims that did not receive as much media coverage. Fact checks would usually be written and published within a matter of hours. Data used included statistics from ONS, international organisations and independent bodies such as the Low Pay Commission and the National Audit Office, peer reviewed academic research, polling and survey data, and Freedom of Information requests.

3. The communications team managed the numerous and varied requests from the media, organized volunteers and social media output, and pitched Full Fact's research to programmes with large viewing or listening figures to ensure the facts reached the widest possible audience.

\section{DEMAND FROM THE MEDIA AND THE PUBLIC}

\subsection{THE MEDIA'S USE OF FULL FACT}

Full Fact received a large number of media requests during the election, displaying varying degrees of statistical literacy. The main type of request was for briefings, on topics as broad as immigration or as specific as figures for the deficit change since 2010, in cash terms. The journalists who requested these were from a wide range of outlets, including tabloids, broadsheets, night-shift staff working on outlets such as the Today programme, and editors of radio or TV shows with high-profile interviews coming up.

Most journalists could in theory find this information themselves. The National Centre for Social Research (NatCen) carried out an independent evaluation of the Election Centre, interviewing both media users and partners (National Centre for Social Research, 2015). The evaluation found that many journalists were confident in their ability to source reliable and trustworthy information, with the ONS and the Office for Budget Responsibility (OBR) most commonly cited as reliable sources. However, faced with the need to fact-check public statements quickly, Full Fact was seen as the most reliable and trustworthy source (compared to other UK fact checkers). NatCen's evaluation also concluded that Full Fact's interventions were thought to be "very well timed" and that researchers were able to "turn quite rough material into a kind of smooth, polished, easily digestible product". It is easy to see why journalists would go straight to Full Fact when working under intense time pressure, often outside of normal office hours. 


\subsection{MEDIA REQUEST CASE STUDIES}

$\boldsymbol{Q} \boldsymbol{\&} \boldsymbol{A}$ Nicky Campbell presents the daily BBC 5 Live phone-in radio show "Your Call", when listeners phone in to question participants in the show. A few weeks before the Election Centre launched, the BBC approached Full Fact to participate in a special health edition to air live for 90 minutes. The idea was for Full Fact researchers to factcheck the claims of health spokespeople for the major UK political parties, namely the Conservatives, Labour, the Liberal Democrats, the Green Party and UKIP, and clear up any factually inaccurate or misleading claims which might arise. After the show, the presenter and producer were so pleased with Full Fact's input that they asked our researchers to continue the Q\&A on Facebook.

Short films Local television network Made TV was hosting debates in marginal seats around the country. They commissioned Full Fact to script, present and advise on graphics for seven videos, to be shown before and during the debates. Each video was two and a half minutes long. This was a new experience for most staff at Full Fact and required careful direction from the campaign's Head of Media, who gave tips such as speaking at 3 words per second, keeping sentences short enough that the presenter would not run out of breath, and remembering that the end is just as important as the beginning.

Live fact-checking The BBC's Victoria Derbyshire Show asked Full Fact to factcheck three special election debates, on the economy, health and immigration, aired in the morning on television channel BBC Two. Full Fact provided live coverage on Twitter, topic briefings for the presenter, and graphs for the $\mathrm{BBC}$ social media team to tweet during the programme.

Debate roundups Buzzfeed asked Full Fact for roundups to be published shortly after the end of the major TV interviews with two party leaders hosted by the journalist Jeremy Paxman, the seven-way and the five-way leader debate. Each roundup was published at around $3 \mathrm{a}$ a.m. that night and contained nine or ten claims. Important caveats were balanced with brief, engaging explanation of statistics and research. Buzzfeed's audience is used to graphics, animations and list-format articles about popular culture, so for each claim Full Fact generally wrote no more than 100 words on average, and worked with the politics editor to produce brightly coloured graphs or images. Topics ranged from the Welsh National Health Service (NHS) staff numbers, debt and deficit, tax paid by Scots compared to the rest of the UK, and child poverty. The majority of permanent and campaign staff worked past midnight after each debate so that a polished, accurate roundup would reach the audience the next morning, before the news had moved on.

Full Fact's expert partners helped with more specialist and complex topics, for example, the Migration Observatory were available at $11 \mathrm{p} . \mathrm{m}$. to help fact-check a claim from Nigel Farage that immigration had directly contributed to the housing crisis.

Correction assistance During the election, the Trussell Trust released figures on foodbank use (the Trust provides food to those in need of emergency food in times of crisis), which were widely reported inaccurately as 'one million people using food banks'. The figures showed uses, not users: the true figure was likely to be around 500,000 people. After persuading the Trussell Trust to issue a clarification, Full Fact received a request for help phrasing a correction from a Guardian journalist who had published one of the inaccurate articles. Full Fact explained the figures to the journalist and suggested an alternative, accurate wording for the correction. 


\subsection{THE PUBLIC AND THE POLITICIANS}

Questions from Full Fact supporters varied in terms of topic and level of detail. Permanent staff were also responsible for answering questions about their topic areas or published articles that came in through e-mail, on Twitter and Facebook. Full Fact used their podcast to solicit questions from readers, who asked the following:

- "Would it be possible to compare the average pay (before or after deductions) of the $1.9 \mathrm{~m}$ jobs created since 2010 with the rest of the UK?"

- "Are academy schools raising standards faster than local authority schools?"

- "What evidence is there that a referendum on the EU will damage the economy?"

- "How many crimes are committed by migrants?"

Full Fact did not receive any similar requests from politicians, or the parties. This may be partly explained by the fact that the communications team had no resources to solicit attention from politicians on the same level that they pursued the media.

\section{ELECTION FACT CHECKS}

\subsection{CONFLICTING CLAIMS: WHO TO TRUST?}

Labour and the Conservatives made seemingly contradictory claims in their manifestos. This left voters with only one certainty: that at least one of the claims was untrustworthy, and maybe both.

Waiting times In the UK, the first port of call for someone in need of medical treatment is a doctor who is referred to as a General Practitioner (GP). The Conservatives said that, "Already millions more people can see a GP 7 days a week, from 8 a.m.- 8 p.m.", and that, "Fewer patients [are] waiting longer than 18, 26 and 52 week targets than in May 2010". Meanwhile Labour claimed that "More people are facing long waits for tests, treatment, or to see a GP".

Hospital waiting times present a complex picture and it is possible to justify both parties' claims by using different measures. The picture on waiting time performance depends on the type of patient. Focusing in on the target that NHS England patients should begin treatment within 18 weeks of a GP referral, performance was worse in 2015 than in 2010 for patients who started treatment in recent months, but better for those who are still on the waiting list. That may seem contradictory, but the two trends are consistent. When more of those who have been waiting a long time enter treatment this shows up as a rise in long waits for treated patients. But fewer long-waiters remain on the waiting list. That is borne out by the figures on 18-week waits for both sets of patients.

Living standards The Conservatives claimed that living standards "will be higher in 2015 than in $2010 \ldots$ with the average family $£ 900$ better off". Labour on the other hand said that "Since 2010 , working people are earning on average $£ 1,600$ less a year after inflation".

Both parties were broadly correct - on their own precise terms. Labour's $£ 1,600$ figure was the change in the real terms median weekly wage from April 2010 to April 2014 , multiplied by 52 . While Labour looked at the change in the median pre-tax weekly wage for employees up to 2014, the Conservatives were looking at the forecast change in post-tax household income from 2010 to 2015. This 'both up and down' phenomenon has since made appearances at Prime Ministers' Questions in conflicting claims about child poverty, much to the bafflement of viewers. 


\subsection{PATHOLOGY AND FULL FACT'S PRE-ELECTION REPORT}

In 2011 Full Fact diagnosed eight common problems from its body of work:

1. No source: the claim doesn't have a source or the source given does not back up the claim.

2. Contentious source: either the source has been published by an unofficial organisation or one with a vested interest; the source has been discredited; the source is obsolete or there is evidence of Churnalism - a journalist using a press release with little critical commentary (see Media Standards Trust, n.d., for more details) - or a lack of verification.

3. Misleading presentation: use of unreasonable hyperbole; important detail is buried; or graphics are confusingly juxtaposed.

4. Poor calculation or rounding: the claim is not precise or is off the mark; the figure has been rounded badly.

5. Insufficient definition: the claimant fails to clarify which of several sources is relevant; the claim is not sufficiently specific; or the claimants' calculation methods are opaque.

6. Insufficient context: the claim is proven to be exaggerated given the bigger picture; the claimant neglects to mention caveats; the claim is correct on technicality but not fair; or the claim is correct but does not corroborate the claimant's point.

7. Unattainable certitude: the claim is theoretically impossible to prove; the claim is too cumbersome for proper research; or the source of the claim is classified (as with many claims about national security).

8. Repeated error: the claimant has made a similar or the same claim before.

Full Fact's election report, published on 4 May, identified a number of pitfalls in politicians' claims made during the election, notably:

- Making comparisons over time (e.g., on zero-hours contracts and educational attainment);

- Further research needed (free schools and universal infant free school meals);

- Knowing what the statistics represent (jobs versus employment and GP appointments);

- Misunderstandings about the baseline (the employment rate); and

- Claims about the limits on the powers of government, for example, on the topic of human rights (which are not written about here).

Below is a description of the context of the claims, Full Fact's analysis of them, and any further action that arose from the research.

\subsection{COMPARISONS OVER TIME}

Literacy and numeracy among children leaving primary school The Conservatives criticised educational standards under Labour, relying on tests given to all children at certain ages (SAT scores) where the nature of the test has changed over time. They claimed that, "Under Labour one in three children left primary school unable to read, write and add up properly, thanks to our reforms and teachers' hard work we have seen that fall to just one in five."

The Conservatives had previously made this claim without the word 'properly' but were compelled to add this caveat after being rebuked by the UK Statistics Authority. It is not possible to compare reading, writing and mathematics performance at age 11 under the Coalition government to performance under the last Labour government. Reading and writing have been tested in a different way since 2012, so test results before and after that 
cannot be compared. For example, teachers now mark the writing tests themselves rather than sending them off for external marking. While the one in three and the one in five figures are broadly accurate (it was $36 \%$ in 2010 and $21 \%$ in 2014), it is not possible to say that this represents a fall.

Zero-hours contracts This is an unofficial term for an employment contract that does not guarantee any working hours. During the election campaign in April, the leader of the Labour party Ed Miliband claimed there was an epidemic of such contracts as three times as many people were on those contracts compared to in 2010.

The statistics available do not and cannot show an "epidemic" in zero-hours contracts. Nor can they accurately show a trend over time. Comparisons of the number of people on zero-hours contracts over time are not reliable, as the ONS makes clear. To measure numbers on such contracts, the ONS uses a survey. This type of contract has gained widespread media attention. Because the survey relies on people knowing their contract type, raised public awareness could lead to an increase in people reporting that they are on zero-hours contracts even if the number of people actually on such contracts is unchanged. Nobody knows how much of the increase really reflects more people on zero-hours contracts, and how much is just increased awareness.

Full Fact sent out a press release just a few hours after this claim had been made. High-profile journalists including the Financial Times' Chris Giles tweeted quotes from the press release. Full Fact's director was interviewed by Sky News, BBC 5 Live and Good Morning Wales, the fact check was quoted in the The Daily Mirror, The Sun, Daily Mail, The Guardian, and The Independent. Labour continued to make their case about employment security but stopped using the flawed claims about zero-hours contracts.

\subsection{FURTHER RESEARCH NEEDED}

Free schools' performance 'Free schools' are funded by the government, and are not subject to local authority control; they do not have to follow the national curriculum, and can set their own pay and conditions for staff. During the election campaign, both the Conservatives and Labour made claims about how well free schools are working, with the Conservatives saying free schools were "delivering better education for the children who need it most" and Labour saying it was a "wasteful and poorly performing" programme.

There were 254 free schools open and only 76 of those were subject to external independent inspections (excluding a further school, which was inspected but closed to re-open under a new sponsor). Official performance results for pupils aged 11 years were available for just 14 primary free schools, and for pupils aged 16 years at the end of compulsory schooling (GCSE) for just 10 secondary free schools. So at that time there was not enough evidence available to say anything meaningful about their performance.

Universal infant free school meals The universal infant free-school-meals policy was introduced to "improve academic attainment and save families money." The Liberal Democrats pledged to extend the policy to all primary pupils.

That was after a pilot scheme was used to test out the policy, the evaluation of which found that performance and healthy eating by primary pupils improved in schools involved in the pilot. But that research was not able to find evidence of significant health benefits resulting from the scheme, nor was it able to connect up evidence for why pupils receiving the meals were seeing their performance improve. Since then, there has been no more research into whether this improved performance has continued and whether or not the free meals were behind the improvement. 
The Liberal Democrats were subsequently careful not to make any claims about the effect of the policy, and pledged to extend the meals to all primary schools "following a full evaluation" of the initial policy.

\subsection{KNOW WHAT YOUR STATISTICS REPRESENT}

Jobs - or people in employment? During the TV debate between seven party leaders, the Prime Minister David Cameron said: "We have created two million jobs." The two million figure was correct, but there is a difference between saying "two million jobs have been created" and "two million more people in employment."

One person can have more than one job, and one job can be done by two or more people, for instance through job-sharing. These differences are important: there are 31 million people in employment, but 33.5 million jobs.

After Full Fact's live coverage of the debate, David Cameron referred to "two million more people in work" - a much fairer reflection of the figures.

GP appointments Earlier during the election period, a claim from Ed Miliband during a speech caused some confusion. He said that a quarter of people "can't get an appointment with their GP within a week."

The best figures on GP waiting times show that $11 \%$ of patients could not get an appointment at all the last time they contacted their GP surgery, while another $14 \%$ saw or spoke to someone a week or more later. It is fair to say a quarter of patients do not get an appointment within a week - but that does not mean they cannot get one. For instance, some people would have been happy to book one week ahead if they wanted to get a repeat prescription, or if their need for an appointment was not urgent.

This simple change of the word "cannot" to "do not" could make this discussion of the figures more accurate. Following this fact check, Labour tweeted that "one in four patients now wait a week or more for a GP appointment" - a fairer comment.

\subsection{BEWARE THE BASELINE}

A record number? The Liberal Democrats and Conservatives claimed that the UK had a record number of people in employment. This record was not a particularly interesting one: records have been made - and broken - bar periods of economic downturn, because the population is increasing. Taking the employment rate rather than the employment numbers - the proportion of people aged 16-64 who are in work another story appeared: before the downturn in 2008 a peak of $73 \%$ of people were in work. That fell as low as $70 \%$, but by election time was up beyond $73 \%$ - a record level on a more meaningful measure.

Accident and Emergency (A\&E) services Another 'record number' claim was common before the election: in January, Labour claimed that there were a record number of people waiting more than four hours in A\&E in England. The Conservatives replied by saying there were a record number of people not waiting more than four hours in A\&E.

Perhaps the most revealing figure is the baseline: there were 22.4 million A\&E attendances in England last year - a record number. That was 1.3 million more than in 2010 and around 3.7 million more than in 2005. 


\section{RECOMMENDATIONS}

\subsection{CLOSING THE GAP: COMMUNICATION TECHNIQUES}

The mantra of everyone concerned with conveying statistical information (politicians, official agencies, fact checkers, and statistics educators) should be: "Start from where my audience is." Statistical communication should be empowering and use plain English wherever possible, educators should use analogies that people can relate to and avoid jargon. This would help to close the gap between technical observation and common sense. Below, we provide some examples of Full Fact communicating statistical concepts, attempting to use accessible language and resonant analogies. Full Fact often uses colloquialisms ("you'd" for "you would", e.g.) that have been edited here to conform to a more formal style.

Regression to the mean The 'Sports Illustrated curse' can be used to explain regression to the mean: Regression to the mean is the name for the fact that things that are very much above or below average on one occasion will generally tend to get closer to the average next time. This is seen in the Sports Illustrated jinx. It turns out that getting on the cover of this magazine, which is an accolade for above-average performance, very often means that you will play less well afterwards. Why? Because there is more room to go down than up, basically.

And in particular, if the probability of your performance is normally distributed (a bell curve), there's much more chance of a near-average performance than a way-aboveaverage one, because most performances cluster around the average. Some players will consistently stay in the way-above-average category (Lionel Messi or Roger Federer, e.g.) but many players who have a great season will have a more average season next. In the same way, if you are growing sunflowers each year and one year there is a really tall bunch, you would not assume that the next year they would be even taller, or even as tall, you would recognise it as an exception and expect them to be more typical the next yearthat is, to regress to the mean.

Comparisons over time The analogy of music sales changing over the last fifty years can be used to explain comparisons over time, for example to explain the effect of cyber crime on crime statistics: If you just counted the number of records sold, you would miss the major changes that moved the market through cassette tapes and CDs to a world where almost all music is bought online (see Seddon, 2011, p. 6). Failing to account for those changes results in failing to understand the true story of music sales over time.

What do your statistics represent? Factual claims that sound the same to a nonexpert are not always what they seem, as in the case about jobs versus people in employment (Section 3.5). A similar word, which may initially sound reasonable sometimes changes the meaning of what gets expressed: Desert? The same word can have very different meanings. Similarly, statistics depend on what exactly they measure. Sometimes they take a complex concept and measure the closest possible thing to it - for example, the notion of social class.

Often we talk about income as a measure of social class, but it is more than a purely economic distinction. So you cannot necessarily take income data as a precise measure of social class. Sometimes official measures of concepts such as 'poverty' and 'employment' are not necessarily the same as common-sense ideas. 
Beware the baseline We hear many claims about record numbers, but when these claims come up, Full Fact questions what is happening to the baseline. We explain it to our audience in this way: For example, it would be no surprise to hear that the number of car crashes has gone up since 100 years ago. There are more cars now than there were 100 years ago. A significant factor in any increase might be just that the baseline has changed. A fairer estimate of accidents would involve comparing the number of accidents to the total number of cars. To account for the baseline, it is best to look at the rate, rather than the level. The UK's population is rising. Many claims that we hear about record numbers of people boil down to that simple fact.

The need for further research Communicators should be willing to say when further research is needed. We are often very quick to assign praise or blame to the government of the day for what happens on its watch, and hear claims too from both the incumbent parties (in the coalition government at the time) about their record in government, and by the opposition parties on things they say that have not worked (or could have gone better). But a frustration for all parties and voters is that sometimes it is just too early to say whether reforms have had a positive or negative effect. It may sound pedantic to say "It is too early to tell" but it might be preferable to pouring money or votes into plans that do not work.

\subsection{TRUST AND STATISTICAL LITERACY}

Just $16 \%$ of the adult population in the UK trust politicians to tell the truth, while $22 \%$ trust journalists to tell the truth (Ipsos Mori, 2016). While at first that might seem like a bad state of affairs, it can also be seen as indicating a certain level of statistical literacy: as Full Fact's work has shown, enough of what the press and the parties say is not accurate - or cannot be taken at face value - so that it makes sense to be sceptical of individual claims. The danger lies in a kind of rational distrust becoming pervasive and undiscerning distrust, and we do not know which category the other $84 \%$ of people, who do not trust politicians to tell the truth, fall into. Full Fact aims to address the problem of low trust in a practical way, and shares the mission of statistical literacy educators in providing people with the tools to judge statistical claims.

To know that numbers cannot be taken at face value can perhaps be seen as one step on the road to statistical literacy and well-informed trust. The next step up understanding and criticising a claim - can require hours of work. In the meantime, Full Fact will continue to provide a short-cut to people who want to understand the claims we hear from politicians and the media. Raising levels of public trust of politicians cannot be only a task for Full Fact and sympathetic organisations, though. It requires some improvement among those in public life in the way they use statistics, in terms of using them accurately and fairly.

\subsection{SUPPORTING INTERMEDIARIES: THE MEDIA AND FULL FACT}

Before the election, some academic partners had reservations about joining the Election Centre, including the pace at which they would be expected to work, distortion of their findings, and increased exposure of their work to the media. In NatCen's independent evaluation report, one participant (presumably a partner organisation) commented that they did not want to let the media drive the way they would answer questions (National Centre for Social Research, 2015). However, they eventually thought the experience of working at a fast pace and often with the media in mind was positive: 
not only for reasons like increased social media followings, but also because reputations were enhanced and there was an overall sense of being part of a community that values accuracy and truth.

Despite the collaborative efforts of the Election Centre, many inaccurate and skewed political statements made it through the media defences and into people's sitting rooms and offices. As part of our election work, we found examples of a party spokesperson talking about one of various poverty trends, without this being queried by a presenter or reporter. Commitment to balance - a laudable aim - may also have led journalists to include inaccurate or unsubstantiated quotes in articles, without challenging them or offering further analysis. This let inaccuracy spread further and allowed parties to use the media as a vehicle for their own messages.

The high level of demand for our Election Centre shows that, when offered help, the media will accept and keep coming back for more. While hesitations about engaging with the media are understandable, the benefits to the public are huge: a more knowledgeable and statistically literate media is able to challenge the statements of politicians and pressure groups. Academics should be willing to engage with the media and other intermediaries that can act as a conduit for experts' knowledge, and should expect to be listened to by the media. In Full Fact's experience, journalists and editors are hungry for alternatives to the usual commentators.

\subsection{AVAILABILITY OF STATISTICIANS AND RESEARCHERS}

Statistical literacy partly depends on the availability of named statisticians on official releases, and properly caveated sources. It is not enough to release spreadsheets of data and expect the media to get the statistics right, or to even use them in programmes or articles. During elections and other important votes, experts and official statisticians could put themselves forward to be available out of hours, either to journalists directly or to be contacted through intermediaries like Full Fact who are able to triage requests effectively.

\subsection{LEARNING FROM MARTIN'S MONEY MANTRAS}

Martin Lewis runs a popular personal finance website (Money Saving Expert, 2017) from where one can download a free, wallet-sized Money Mantra Card which users can print off and cut out. It contains three questions people should ask themselves before they spend money in a shop (see Figure 2).

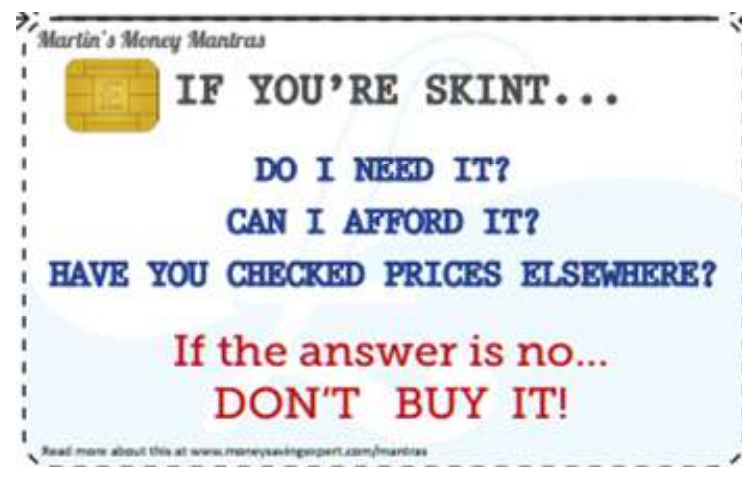

Figure 2. Front side of money mantra card - put front and back together as a credit card 
Full Fact has its own version of these tips, albeit conveyed verbally rather than as a print-out credit-card sized image: 1.Where has the data come from? 2. What are they measuring? 3. What have they done with the data? Teachers could adopt these, or choose new mantras. Whatever they choose, it is important that the questions are simple, memorable and promoted consistently by educators.

Basic statistical literacy should not be presented as something only experts can achieve, but as common sense, simple enough to slip into your wallet on a credit-card sized piece of paper.

\section{REFERENCES}

Ipsos MORI (2016). Politicians are still trusted less than estate agents, journalists and bankers. Ipsos MORI veracity index 2015: Trust in professions.

[Online: www.ipsos-mori.com/researchpublications/researcharchive/3685/Politiciansare-still-trusted-less-than-estate-agents-journalists-and-bankers.aspx]

Longva, S. (2004). Indicators for democratic debate: Informing the public at general elections. Methods and documentation. Statistics Norway. [Online:

www.ssb.no/en/valg/artikler-og-publikasjoner/indicators-for-democratic-debate?fane=om\#content]

Media Standards Trust (n.d.). Churnalism.

[Online: mediastandardstrust.org/churnalism/]

Money Saving Expert (2017). Money mantra card.

[Online: www.moneysavingexpert.com/shopping/money-mantras]

National Centre for Social Research (2015). Full fact election centre evaluation. [Online: fullfact.org/media/uploads/2015_election_centre_report_by_national_centre_for_social_research.pdf]

Ofcom (2014). News consumption in the UK - 2014 Report. [Online: stakeholders.ofcom.org.uk/binaries/research/tv-research/news/2014/News_Report_2014.pdf]

ONS (2015). UK labour market, March 2015. Office for National Statistics. [Online: www.ons.gov.uk/ons/rel//ms/labour-market-statistics/march-2015/statistical-bulletin.html]

Seddon, C. (2011). Lifestyles and social participation. Social Trends, 41(1), 146-180.

[Online: link.springer.com/article/10.1057/st.2011.7]

\section{ACKNOWLEDGEMENTS}

Many thanks to the Nuffield Foundation and the 1,297 people who supported Full Fact's crowdfunding campaign. Thanks to our election collaborators: the Health Foundation, the Institute for Criminal Policy Research, Migration Observatory, the National Foundation for Educational Research, the Nuffield Trust, and to other contributors. Thanks to volunteers and staff who made the Election Centre a success.

PHOEBE ARNOLD

Full Fact

2 Carlton Gardens, London SW1Y 5AA 